\title{
Micropropagação e aclimatização de gerânio (Pelargonium graveolens L.)
}

\author{
ARRIGONI-BLANK, M.F.*; ALMEIDA, S.A.; OLIVEIRA, A.C.L.; BLANK, A.F. \\ Universidade Federal de Sergipe, Avenida Marechal Rondon, s/n, Bairro Jardim Rosa Elze, CEP: 49100-000, São \\ Cristóvão-Brasil *arrigoni@ufs.br; fátima.blank@gmail.com
}

RESUMO: O gerânio (Pelargonium graveolens L.) é uma planta medicinal e aromática nativa do sul da África, cujo óleo essencial é amplamente empregado nas indústrias de perfumaria e cosmético, além de ser usado como terapêutico. Avaliou-se o efeito da luminosidade e dos reguladores de crescimento BAP e ANA na multiplicação in vitro e o uso de diferentes substratos na aclimatização de mudas micropropagadas. Foram avaliadas as concentrações 0; 0,5; 1,0 e 2,0 $\mathrm{mg} \mathrm{L}^{-1}$ de BAP, 0; 0,1 e 0,5 $\mathrm{mg} \mathrm{L}^{-1}$ de ANA e duas condições de luminosidade (ausência e presença de luz), em esquema fatorial $4 \times 3 \times 2$; para a aclimatização foram utilizados quatro substratos, pó de coco + Biosafra ${ }^{\circledR}(3-12-6)\left(12 \mathrm{~g} \mathrm{~L}^{-1}\right)+$ calcário $\left(1 \mathrm{~g} \mathrm{~L}^{-1}\right)(\mathrm{PCBC})$; pó de coco + Biosafra $^{\circledR}(3-12-6)\left(12 \mathrm{~g} \mathrm{~L}^{-1}\right)+$ calcário $\left(1 \mathrm{~g} \mathrm{~L}^{-1}\right)+$ vermiculita (1:1) (PCBCV 1:1); pó de coco + Biosafra ${ }^{\circledR}(3-12-6)\left(12 \mathrm{~g} \mathrm{~L}^{-1}\right)+$ calcário $\left(1 \mathrm{~g} \mathrm{~L}^{-1}\right)+$ vermiculita (PCBCV 2:1) e vermiculita e adição semanal de sais MS (VS). Para a micropropagação de $P$. graveolens a utilização de $1,3 \mathrm{mg} \mathrm{L}^{-1}$ de BAP e $0,5 \mathrm{mg} \mathrm{L}^{-1}$ de ANA é eficiente na regeneração direta de plantas de gerânio, sendo a condição de escuro a mais indicada por proporcionar o maior número de brotos por explante. Para a aclimatização das mudas de gerânio, os melhores resultados foram obtidos em mudas aclimatizadas no substrato vermiculita com adição semanal de sais de MS seguido do substrato PCBCV 1:1.

Palavras-chave: Pelargonium graveolens, planta medicinal e aromática, multiplicação in vitro, aclimatização, substrato

ABSTRACT: Micropropagation and acclimatization of geranium (Pelargonium graveolens L.). Geranium (Pelargonium graveolens L.) is a medicinal and aromatic plant native to the south of Africa and whose essential oil is widely used by perfume and cosmetic industries, as well as in therapeutics. The effect of luminosity and growth regulators BAP and NAA on in vitro multiplication was evaluated, together with the use of different substrates on the acclimatization of micropropagated seedlings. The evaluated concentrations were $0,0.5,1.0$ and $2.0 \mathrm{mg} \mathrm{L}^{-1} \mathrm{BAP} ; 0,0.1$ and $0.5 \mathrm{mg}$ $\mathrm{L}^{-1} \mathrm{NAA}$; and two luminosity conditions (absence and presence of light), in a $4 \times 3 \times 2$ factorial arrangement. For acclimatization, four substrates were tested: coconut dust + Biosafra ${ }^{\circledR}(3-12-6)$ $\left(12 \mathrm{~g} \mathrm{~L}^{-1}\right)+$ limestone $\left(1 \mathrm{~g} \mathrm{~L}^{-1}\right)(\mathrm{CDBL})$; coconut dust + Biosafra ${ }^{\boxplus}(3-12-6)\left(12 \mathrm{~g} \mathrm{~L}^{-1}\right)+$ limestone $(1 \mathrm{~g}$ $\left.\mathrm{L}^{-1}\right)+$ vermiculite (1:1) (CDBLV 1:1); coconut dust + Biosafra ${ }^{\circledast}(3-12-6)\left(12 \mathrm{~g} \mathrm{~L}^{-1}\right)+$ limestone $(1 \mathrm{~g}$ $\left.\mathrm{L}^{-1}\right)+$ vermiculite (CDBLV 2:1); and vermiculite with weekly addition of MS salts (VS). For $P$. graveolens micropropagation, the use of $1.3 \mathrm{mg} \mathrm{L}^{-1} \mathrm{BAP}$ and $0.5 \mathrm{mg} \mathrm{L}^{-1} \mathrm{NAA}$ is efficient for the direct regeneration of geranium plants, and the dark condition is the most suitable since it provides a larger number of shoots per explant. For the acclimatization of geranium seedlings, the best results were obtained with seedlings acclimatized in the substrate vermiculite with weekly addition of MS salts, followed by the substrate CDBLV 1:1.

Key words: Pelargonium graveolens, medicinal and aromatic plant, in vitro multiplication, acclimatization, substrate

\section{INTRODUÇÃO}

O Pelargonium graveolens L. (Geraniaceae) conhecido como gerânio ou malva-cheirosa é uma planta aromática, originária da África do Sul (Simon

et al., 1984). O aroma doce e quente, semelhante ao de pétalas de rosas é comercialmente conhecido como óleo de gerânio e amplamente usado em

Recebido para publicação em 25/05/2009

Aceito para publicação em 27/12/2010

Rev. Bras. Pl. Med., Botucatu, v.13, n.3, p.271-275, 2011. 
sabonetes e nas indústrias de perfumaria e cosméticos (Saxena et al., 2000), sendo também utilizado como terapêutico (aromaterapia) para combater problemas da menopausa, de pele, tensão nervosa e ansiedade (Rao, 2002).

A micropropagação é uma das técnicas de cultura de tecidos que vem sendo bastante empregada para a manutenção de germoplasma, bem como, a propagação comercial de muitas plantas medicinais e aromáticas, com o objetivo de se obter mudas com qualidades agronômicas desejáveis, indexadas, livres de patógenos e com elevado padrão genético, para síntese de metabólitos secundários e/ou produção de óleos essenciais (França, 2004).

Grande parte dos trabalhos de regeneração de plantas do gênero Pelargonium foi realizada a partir de explantes jovens, tais como hipocótilos (Senaratha et al., 1999) ou hipocótilo e cotilédones (Murth et al., 1996), via embriogênese somática. Poucas informações estão disponíveis sobre organogênese e regeneração de plantas usando explantes maduros (Hassanein \& Dorion, 2005). Trabalhando com Pelargonium x hortorum, Agarwal \& Ranu (2000) obtiveram alta taxa de regeneração do pecíolo foliar, enquanto que Hassanein \& Dorion (2005) obtiveram $100 \%$ de regeneração direta em $P$. capitatum e $P$. graveolens utilizando segmento foliar e meio MS (Murashige \& Skoog, 1962) suplementado com 0,5 $\mathrm{mg} \mathrm{L}^{-1}$ de ANA em combinação com $1 \mathrm{mg} \mathrm{L}^{-1}$ de BAP e zeatina na ausência de luz.

$\mathrm{Na}$ aclimatização, a escolha do substrato pode ser decisiva para o sucesso dessa fase. $O$ substrato deve ter baixa densidade, rico em nutrientes, composição química equilibrada e física uniforme, boa aeração e drenagem, boa coesão entre as partículas e raízes (Hoffmann, 2002). Quando se trabalha em grande escala, mesmo com percentual relativamente pequeno de morte das plantas, a escolha errada do substrato pode significar prejuízo econômico considerável devido ao alto investimento e emprego de mão-de-obra nessa técnica (Terceiro Neto et al., 2004).

O presente trabalho teve como objetivo avaliar o efeito dos reguladores de crescimento 6benzilaminopurina (BAP) e ácido naftalenoacético (ANA) na micropropagação de gerânio, assim como verificar o melhor substrato para a aclimatização de mudas oriundas do cultivo in vitro.

\section{MATERIAL E MÉTODO}

Os ensaios foram realizados no Laboratório de Cultura de Tecidos e Melhoramento Vegetal do Departamento de Engenharia Agronômica (DEA) da Universidade Federal de Sergipe (UFS), localizado no município de São Cristóvão-SE, Brasil. O meio de cultura utilizado foi o MS (Murashige \& Skoog, 1962), acrescidos de $30 \mathrm{~g} \mathrm{~L}^{-1}$ de sacarose e $7 \mathrm{~g} \mathrm{~L}^{-1}$ de ágarágar. $\mathrm{O} \mathrm{pH}$ do meio foi ajustado para 6,0 $\pm 0,1 \mathrm{e}$ submetido a autoclavagem por 15 minutos (à $121 \pm$ $1^{\circ} \mathrm{C}$ e pressão de $1,05 \mathrm{~atm}$ ). Com o auxílio de bisturi e pinça, constantemente flambados, os explantes foram seccionados com cerca de 10 a $15 \mathrm{~mm}$ e inoculados. As culturas foram mantidas em sala de crescimento com temperatura controlada de $25 \pm 2^{\circ} \mathrm{C}$, fotoperíodo de 12 horas e intensidade luminosa de $60 \mathrm{mmol} \mathrm{m}^{-2} \mathrm{~s}^{-1}$, proveniente de luz fluorescente branca fria.

\section{e ANA}

Efeito da luminosidade e interação de BAP

O delineamento experimental utilizado foi o inteiramente casualizado em esquema fatorial de $4 x$ $3 \times 2$, sendo quatro concentrações $(0 ; 0,5 ; 1,0$ e 2,0 $\mathrm{mg} \mathrm{L}^{-1}$ ) de 6-benzilaminopurina (BAP) e três concentrações $\left(0 ; 0,1\right.$ e $\left.0,5 \mathrm{mg} \mathrm{L}^{-1}\right)$ de ácido naftalenoacético (ANA) e duas condições de luminosidade (presença e ausência), com cinco repetições. Cada unidade experimental foi constituída de quatro tubos de ensaio contendo $15 \mathrm{~mL}$ de meio de cultura. Como fontes de explantes foram utilizados segmentos foliares provenientes de plantas estabelecidas in vitro.

Aos 40 dias após a implantação do ensaio, foram avaliadas as variáveis regeneração (\%), número de brotos por explante e massa seca de parte aérea (mg). Os dados obtidos foram submetidos a análise de variância pelo teste $\mathrm{Fe}$, quando significativas, as médias foram comparadas pelo teste de Tukey $(p \leq 0,05)$ e regressões polinomiais.

\section{Aclimatização de mudas micropropagadas}

Foram utilizadas mudas micropropagadas do genótipo 001 de P. graveolens, realizando-se a lavagem em água corrente para eliminação do meio de cultura aderido às raízes e transferidas para bandejas de poliestireno expandido com 72 alvéolos, contendo diferentes tratamentos e mantidas em ambiente protegido com tela sombrite $50 \%$ e sistema de nebulização intermitente garantindo alta umidade relativa.

O delineamento experimental foi 0 inteiramente casualizado, utilizando-se quatro substratos: pó de coco + Biosafra ${ }^{\circledR}(3-12-6)\left(12 \mathrm{~g} \mathrm{~L}^{-1}\right)$ + calcário (1 $\left.\mathrm{g} \mathrm{L}^{-1}\right)(\mathrm{PCBC})$; pó de coco + Biosafra ${ }^{\circledR}$ (3-12-6) (12 $\left.\mathrm{g} \mathrm{L}^{-1}\right)+$ calcário $\left(1 \mathrm{~g} \mathrm{~L}^{-1}\right)+$ vermiculita (1:1) (PCBCV 1:1); pó de coco + Biosafra ${ }^{\circledR}(3-12-6)$ $\left(12 \mathrm{~g} \mathrm{~L}^{-1}\right)+$ calcário $\left(1 \mathrm{~g} \mathrm{~L}^{-1}\right)+$ vermiculita $(\mathrm{PCBCV}$ 2:1) e vermiculita e adição semanal de sais MS (VS), distribuídas em cinco repetições. Cada unidade experimental foi constituída por quatro plantas.

Aos 40 dias foram avaliadas as variáveis sobrevivência (\%), altura da planta $(\mathrm{cm})$, número de brotos, comprimento da raiz $(\mathrm{cm})$, número de folhas, 
massa seca e fresca da parte aérea $(\mathrm{g})$. Os resultados foram submetidos à análise de variância pelo teste $F$ e as médias, quando significativas, foram comparadas pelo teste de Tukey a $5 \%$ de probabilidade.

\section{RESULTADO E DISCUSSÃO}

\section{e ANA}

Efeito da luminosidade e interação de BAP

Houve interação entre BAP e ANA e luminosidade na regeneração de plantas e número de brotos por explante de gerânio a partir de segmentos foliares (Tabelas 1 e 2). Na presença de luz, a maior porcentagem de regeneração é representada por uma equação quadrática, sendo a concentração de $1,3 \mathrm{mg} \mathrm{L}^{-1}$ de BAP e $0,5 \mathrm{mg} \mathrm{L}^{-1}$ de ANA, o que promoveu a maior regeneração de plantas (50\%). Entretanto, na ausência de luminosidade, houve uma maior porcentagem de regeneração de plantas (cerca de $90 \%$ ), quando utilizado $1,2 \mathrm{mg} \mathrm{L}^{-1}$ de BAP associado com 0,1 $\mathrm{mg} \mathrm{L}^{-1}$ de ANA (Tabela 1). Resultados semelhantes foram obtidos com Pelargonium x hortorum (95\%) e P. capitatum (100\%) (Hassanein \& Dorion, 2005).

Em relação ao número de brotos por explante, a condição de escuro favoreceu o maior número de brotos, sendo todos os tratamentos representados por equações quadráticas, exceto quando foi utilizado $0,1 \mathrm{mg} \mathrm{L}^{-1}$ de ANA e em todas as concentrações de BAP, na presença de luz, onde apesar de apresentar regeneração de plantas (Tabela 1), não foi possível a contagem do número de brotos em virtude do tamanho dos mesmos (menores de 2 $\mathrm{mm}$ ) (Tabela 2). A utilização de $0,1 \mathrm{mg} \mathrm{L}^{-1}$ de ANAe $1,2 \mathrm{mg} \mathrm{L}^{-1}$ de BAP, na ausência de luz, proporcionou 20,9 brotos por explante, ao passo que a utilização de $0,5 \mathrm{mg} \mathrm{L}^{-1}$ de ANA e $1,0 \mathrm{mg} \mathrm{L}^{-1}$ de BAP não apresentou diferenças significativas entre as duas condições de luminosidade, proporcionando uma média de 13 brotos por explante. Resultados diferentes foram obtidos em trabalhos com Pelargonium $\mathrm{x}$ hortorum, onde o meio contendo 10,0 $\mathrm{mg} \mathrm{L}^{-1}$ de BAP e 1,0 $\mathrm{mg} \mathrm{L}^{-1}$ de ANA proporcionou uma média de 4,9 $\pm 2,5$ brotos por explante (Gómez, 2002). Já em trabalhos com o P. graveolens, Hassanein \& Dorion (2005) obtiveram cerca de 7,3 brotos por explante, utilizando $0,5 \mathrm{mg} \mathrm{L}^{-1}$ de ANA e $1,0 \mathrm{mg} \mathrm{L}^{-1}$ de BAP e zeatina, na ausência de luz. Os resultados obtidos no presente trabalho mostram-se superiores, quando comparados aos resultados obtidos pelos autores acima citados, uma vez que foi

TABELA1. Regeneração (\%) in vitro de plântulas de gerânio ( $P$. graveolens) em função da interação de BAP x ANA $x$ luminosidade.

\begin{tabular}{|c|c|c|c|}
\hline \multirow[t]{2}{*}{$\mathrm{BAP}\left(\mathrm{mg} \mathrm{L}^{-1}\right)$} & \multicolumn{3}{|c|}{ ANA $\left(\mathrm{mg} \mathrm{L}^{-1}\right)$} \\
\hline & 0,0 & 0,1 & 0,5 \\
\hline & & --1 & --------------------------------- \\
\hline 0,0 & $0,0 \mathrm{aA}$ & $0,0 \mathrm{aB}$ & $0,00 \mathrm{aB}$ \\
\hline 0,5 & $0,0 \mathrm{bB}$ & $0,0 \mathrm{bB}$ & $41,67 \mathrm{aB}$ \\
\hline 1,0 & $0,0 \mathrm{aB}$ & $0,0 \mathrm{aB}$ & $50,00 \mathrm{aB}$ \\
\hline 2,0 & 25,0 aA & $25,0 \mathrm{aB}$ & $41,67 \mathrm{aB}$ \\
\hline \multirow[t]{2}{*}{ Equação $(\mathrm{Y})=$} & $3,863+22,803 X-2,272 X^{2}$ & $0,681-10,6818 X+11,3636 X^{2}$ & $2,045+84,6212 X-32,5757 X^{2}$ \\
\hline & $R^{2}=79,79$ & $R^{2}=98,79^{\star}$ & $R^{2}=94,54^{\star \star}$ \\
\hline & 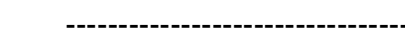 & ---------- Escuro ------------- & --------------------------------- \\
\hline 0,0 & $0,0 \mathrm{bA}$ & 41,67 aA & 58,33 aA \\
\hline 0,5 & $25,0 \mathrm{bA}$ & $58,33 \mathrm{abA}$ & 83,33 aA \\
\hline 1,0 & $16,7 \mathrm{bA}$ & 91,67 aA & 83,33 aA \\
\hline 2,0 & 41,7 aA & 66,67 aA & $75,00 \mathrm{aA}$ \\
\hline \multirow[t]{2}{*}{ Equação $(Y)=$} & $5,00+18,0952 X$ & $37,803+77,1970 X-31,0606 X^{2}$ & $60,151+46,515 X-19,6970 X^{2}$ \\
\hline & $R^{2}=79,34^{* *}$ & $R^{2}=79,57^{\star *}$ & $R^{2}=91,74^{*}$ \\
\hline CV (\%) & & 32,76 & \\
\hline
\end{tabular}

*Médias seguidas das mesmas letras minúsculas nas linhas e maiúsculas entre luminosidades, não diferem estatisticamente entre si pelo teste de Tukey $(p \leq 0,05)$

Rev. Bras. Pl. Med., Botucatu, v.13, n.3, p.271-275, 2011. 
possível obter maior número de brotos por explante utilizando concentrações menores de reguladores de crescimento. Resultados assim são úteis no que diz respeito à redução dos custos de produção comercial dessas mudas.

\section{Aclimatização de mudas micropropagadas}

As variáveis sobrevivência, altura de planta, massa fresca de parte aérea e seca de raiz foram afetadas significativamente pelas misturas de substratos utilizados na aclimatização de gerânio. Já o comprimento de raiz, número de brotos, número de folhas e massa seca de parte aérea não houve diferenças significativas entre os substratos (Tabelas 3 e 4).

De acordo com a Tabela 3, as maiores porcentagens de sobrevivência de plantas foram obtidas com os substratos VS, PCBC, e PCBCV (1:1). Na aclimatização de plântulas de coqueiro-anão as maiores taxas de sobrevivência $(58,33 \%)$ foram observadas na mistura areia lavada e pó de casca de coco seco (Lédo et al., 2007). O uso de pó da casca de coco é de grande utilidade, uma vez que o aproveitamento de resíduos da agroindústria surge como uma solução para problemas econômicos, sociais e ambientais (Silveira et al., 2002).

Em relação à altura de plantas, o maior valor foi proporcionado pela utilização de vermiculita, não diferenciando significativamente dos substratos PCBCV (1:1) e PCBCV (2:1) (Tabela 3). Esta mesma tendência foi observada em relação à massa fresca de parte aérea (Tabela 4). Trabalhando com violeta africana (Saintpaulia ionantha Wendl), Terceiro Neto et al. (2004) observaram que os melhores resultados foram obtidos nas mudas aclimatadas nos substratos comerciais plantagro e bioplant, seguidos pelo pó de coco seco e vermiculita. Resultados diferentes foram obtidos na aclimatização de mudas micropropagadas de porta-enxerto de macieira 'Marubakaido', que ao contrário do obtido com gerânio, a vermiculita mostrou-se o substrato menos eficiente (Hoffmann et al., 2001).

TABELA 3. Médias de sobrevivência (\%), altura de planta $(\mathrm{cm})$, comprimento de raiz $(\mathrm{cm})$, número de folhas e brotos na aclimatização de plantas de $P$. graveolens em diferentes misturas de substratos.

\begin{tabular}{lccccc}
\hline Substrato $^{1}$ & $\begin{array}{c}\text { Sobrevivência } \\
(\%)\end{array}$ & $\begin{array}{c}\text { Altura de } \\
\text { planta }(\mathrm{cm})\end{array}$ & $\begin{array}{c}\text { Comprimento } \\
\text { de Raiz }(\mathrm{cm})\end{array}$ & $\begin{array}{c}\text { Número } \\
\text { de Brotos }\end{array}$ & $\begin{array}{c}\text { Número } \\
\text { de folhas }\end{array}$ \\
\hline PCBC & $55,0 \mathrm{ab}$ & $2,5 \mathrm{~b}$ & $7,4 \mathrm{a}$ & $0,90 \mathrm{a}$ & $7,1 \mathrm{a}$ \\
PCBCV 1:1 & $85,0 \mathrm{ab}$ & $4,1 \mathrm{ab}$ & $10,2 \mathrm{a}$ & $1,75 \mathrm{a}$ & $13,0 \mathrm{a}$ \\
PCBCV 2:1 & $45,0 \mathrm{~b}$ & $3,6 \mathrm{ab}$ & $7,4 \mathrm{a}$ & $1,23 \mathrm{a}$ & $9,0 \mathrm{a}$ \\
VS & $95,0 \mathrm{a}$ & $6,3 \mathrm{a}$ & $13,0 \mathrm{a}$ & $1,90 \mathrm{a}$ & $14,3 \mathrm{a}$ \\
\hline CV $(\%)$ & 37,05 & 39,35 & 35,50 & 44,88 & 37,09 \\
\hline
\end{tabular}

*Médias seguidas das mesmas letras minúsculas nas colunas, não diferem estatisticamente entre si pelo teste de Tukey ( $\mathrm{p} \leq 0,05)$. ${ }^{1} \mathrm{PCBC}$

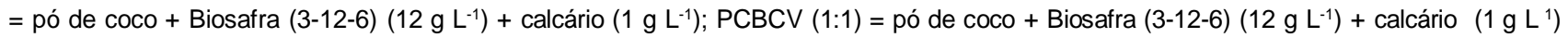
+ vermiculita (1:1); PCVCV (2:1) = pó de coco + Biosafra (3-12-6) $\left(12 \mathrm{~g} \mathrm{~L}^{-1}\right)$ + calcário $\left(1 \mathrm{~g} \mathrm{~L}^{-1}\right)$ + vermiculita $(2: 1)$ e VS = vermiculita + sais MS.

TABELA4. Massa fresca de parte aérea (g) e massa seca de parte aérea e raiz na aclimatização de plantas de $P$. graveolens em diferentes misturas de substratos.

\begin{tabular}{lccc}
\hline Substrato $^{1}$ & Massa fresca de & \multicolumn{2}{c}{ Massa seca $(\mathrm{g})$} \\
\cline { 3 - 4 } & parte aérea $(\mathrm{g})$ & Parte aérea & Raiz \\
\hline PCBC & $55,84 \mathrm{ab}$ & $8,30 \mathrm{a}$ & $0,06 \mathrm{~b}$ \\
PCBCV 1:1 & $86,26 \mathrm{ab}$ & $11,92 \mathrm{a}$ & $0,10 \mathrm{~b}$ \\
PCBCV 2:1 & $45,68 \mathrm{~b}$ & $8,62 \mathrm{a}$ & $0,05 \mathrm{~b}$ \\
VS & $96,47 \mathrm{a}$ & $14,89 \mathrm{a}$ & $0,19 \mathrm{a}$ \\
\hline CV $(\%)$ & 35,28 & 34,88 & 40,22 \\
\hline
\end{tabular}

\footnotetext{
*Médias seguidas das mesmas letras minúsculas nas colunas, não diferem estatisticamente entre si pelo teste de Tukey ( $\mathrm{p} \leq 0,05)$. ${ }^{1} P C B C$

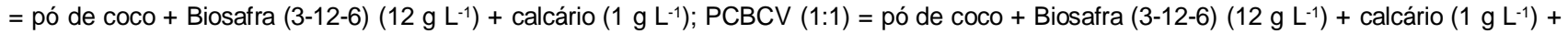
vermiculita (1:1); PCVCV $(2: 1)=$ pó de coco + Biosafra (3-12-6) $\left(12 \mathrm{~g} \mathrm{~L}^{-1}\right)+$ calcário $\left(1 \mathrm{~g} \mathrm{~L}^{-1}\right)$ + vermiculita $(2: 1)$ e VS = vermiculita + sais MS.
}

Rev. Bras. PI. Med., Botucatu, v.13, n.3, p.271-275, 2011. 
Para a micropropagação de $P$. graveolens a utilização de $1,3 \mathrm{mg} \mathrm{L}^{-1}$ de BAP e $0,5 \mathrm{mg} \mathrm{L}^{-1}$ de ANA é eficiente na regeneração direta de plantas de gerânio, sendo a condição de escuro a mais indicada. Essa mesma condição promoveu o maior número de brotos por explante. De um modo geral o melhor substrato utilizado na aclimatização de plantas micropropagadas foi a vermiculita com adição semanal de sais de MS seguido do substrato PCBCV $1: 1$.

\section{AGRADECIMENTO}

Os autores agradecem ao CNPq pela bolsa de mestrado concedida ao segundo autor e de produtividade do último autor e à UFS, através do PAIRD, pelo financiamento da pesquisa.

\section{REFERÊNCIA}

AGARWAL, P.K.; RANU, R.S. Regeneration of plantletes from leaf and petiole explants of Pelargonium $x$ hortorum. In vitro Cell Development Biology - Plant, v.36, p.392-7, 2000.

FRANÇA, S.C. Abordagens biotecnológicas para a obtenção de substâncias ativas. In: SIMÕES, C.M.O. et al. Farmacognosia: da planta ao medicamento. Porto Alegre/Florianópolis: Ed. da UFRGS/Ed. da UFSC, 2004. p.123-46.

GÓMEZ, M.A. Biotecnología aplicada a la mejora de Pelargonium. 2002. 142p. Tese (Doutorado) Departamento de Genética, Universidad Complutense de Madrid, Madrid.

HASSANEIN, A.; DORION, N. Efficient plant regeneration system from leaf discs of zonal (Pelargonium $\mathrm{x}$ hortorum) and two scented ( $P$. capitatum and $P$. graveolens) geraniums. Plant Cell Tissue and Organ Culture, v.83, p.231-40, 2005.

HOFFMANN, A. et al. Efeito de substratos na aclimatização de plantas micropropagadas do portaenxerto de macieira 'Marubakaido'. Ciência e Agrotecnologia, v.25, n.2, p.462-7, 2001.

HOFFMANN, A. Aclimatação de mudas produzidas in vitro e in vitro. Informe Agropecuário, v.23, p.21-4, 2002.

LÉDO, A.S. et al. Cultivo in vitro de embriões zigóticos e aclimatação de plântulas de coqueiro-anão. Pesquisa Agropecuária Brasileira, v.42, n.2, p.147-54, 2007. MURASHIGE, T.; SKOOG, F. A revised medium for rapid growth and bioassys with tobacco tissue cultures. Physiologia Plantarum, v.15, p.473-9, 1962.

MURTH, B.N.S.; SINGH, R.P.; SAXENA, P.K. Induction of high-frequency somatic embryogenesis in geranium (pelargonium x hortorum Bailey cv Ringo Rose) cotyledonary cultures. Plant Cell Report, v.15, p.423-6, 1996.

RAO, B.R.R. Biomass yield, essential oil yield and essential oil composition of rose-scented geranium (Pelargonium species) as influenced by row spacings and intercropping with cornmint (Mentha arvensis L. f. piperascens Malinv. Ex Holmes). Industrial Crops and Products, v.16, p.133-44, 2002.

SAXENA, G. et al. An efficient in vitro produce for micropropagation and generation of somaclones of rose scented Pelargonium. Plant Science, v.155, p.133-40, 2000.

SENARATHA, T. et al. Smoke-saturated water promotes somatic embryogenesis in geranium. Plant Growth Regulator, v.28, p.95-9, 1999.

SILVEIRA, E.B. et al. Pó de coco como substrato para produção de mudas de tomateiro. Horticultura Brasileira, v.20, n.2, p.211-6, 2002.

SIMON, J.E.; CHADWICK, A.F.; CRAKER, L.E. Herbs: an indexed bibliography 1971-1980: the scientific literature on selected herbs, and aromatic and medicinal plants of the temperate zone. Hamden: Archon Books, 1984. $770 \mathrm{p}$.

TERCEIRO NETO, C.P.C. et al. Efeito da concentração salina da solução nutritiva na aclimatização de plantas micropropagadas de violeta africana (Saintpaulia ionantha Wendl). Revista de Biologia e Ciências da Terra, v.4, n.2, p.1-8, 2004. 